\title{
Teores de ácidos graxos em ovos comerciais convencionais e modificados com ômega-3
}

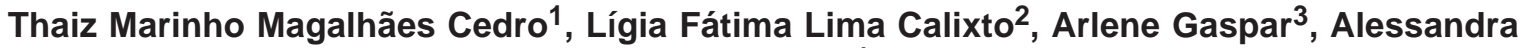 \\ Souza Hora ${ }^{4}$
}

\footnotetext{
1 Pós-Graduação em Zootecnia, UFRRJ.

2 Departamento de Produção Animal, IZ, UFRRJ.

${ }^{3}$ Departamento de Tecnologia de Alimentos, IT, UFRRJ.

${ }^{4}$ Curso de Graduação em Zootecnia, UFRRJ.
}

RESUMO - Objetivou-se comparar os teores de ácidos graxos em ovos comerciais convencionais e em ovos modificados com ômega-3. Foram utilizadas 864 poedeiras da linhagem Isa Brown aleatoriamente distribuídas em dois grupos, de modo que cada gaiola com quatro aves foi considerada uma repetição, totalizando 216 repetições. No grupo para produção de ovos convencionais, as aves foram alimentadas durante toda a vida produtiva com ração à base de milho e farelo de soja, enquanto, no grupo para produção de ovos modificados, foram alimentadas, a partir da $22 \underline{a}$ semana de idade, com ração contendo $1,5 \%$ de substrato de algas marinhas e 1,8\% de óleo de peixe. Foram coletados, aleatoriamente, 180 ovos de cada grupo de poedeira (totalizando 360 ovos), que foram distribuídos em delineamento de blocos ao acaso, considerando cada ovo uma repetição. Os ovos modificados com ômega-3 apresentaram menores de índice de gema, mas não diferiram dos ovos convencionais quanto aos demais parâmetros de qualidade. As médias de ácidos graxos poliinsaturados ômega-3 e de ácidos graxos monoinsaturados foram mais altas nos ovos modificados. As relações entre ácidos graxos poliinsaturados e saturados e entre ômega-6 e ômega-3 nos ovos modificados foram próximas ao ideal estimado para alimentação humana. As médias de ácidos graxos poliinsaturados da série ômega-6 e de ácidos graxos saturados nos ovos convencionais foram significativamente maiores que dos ovos modificados com ômega-3.

Palavras-chave: lipídios na gema, ovos para consumo, qualidade dos ovos

\section{Fatty acids levels in conventional and designer omega-3 commercial eggs}

\begin{abstract}
The objective of this work was to compare the levels of fatty acids between conventional commercial eggs and designer omega-3 eggs. It was used 864 Isa Brown line laying hens randomly distributed in two groups, so each cage with four birds was considered a replicate, totalizing 216 repetitions. In the group for production of conventional eggs, birds were fed corn- and soybean-based rations during the entire productive life while in the group for production of designer eggs, they were fed, from the $22^{\text {nd }}$ week of age, rations with $1.5 \%$ of marine algae substrate and $1.8 \%$ fish oil. A total of 180 eggs was randomly collected from each group of the laying hens (totalizing 360 eggs), which were distributed in a randomized block design, considering each egg a replicate. Designer omega-3 eggs showed the lowest yolk index, but they did not differ from the conventional eggs regarded to the other parameters of quality. Means of omega-3 polyunsaturated fatty acids and monounsaturated fatty acids were higher for designer eggs. The relationships between polyunsaturated and saturated fatty acids and among omega- 6 and omega- 3 in designer eggs were close to the ideal estimated for human consumption. Means of the polyunsaturated fatty acids from the omega- 6 series and of saturated fatty acids were significantly higher than omega- 3 designer eggs.
\end{abstract}

Key Words: egg quality, table eggs, yolk lipids

\section{Introdução}

Visando atingir o consumidor preocupado com a ingestão de alimentos mais saudáveis, a indústria avícola vem promovendo o enriquecimento de ovos com ácidos graxos poliinsaturados da série ômega-3 (AGP $\omega$-3), os também chamados ovos PUFA (polyunsaturated fatty acid). O interesse da população pelos teores dietéticos de $\omega$-3 advêm da sua importância na preservação da saúde cardiovascular, mental e de alguns tipos de câncer (Simopoulos, 2000; Madruga et al., 2008).

A produção de ovos modificados com $\omega$-3 é possível pelo fornecimento de fontes ricas nestes ácidos graxos na dieta de poedeiras comerciais. Estudos mostram que a 
inclusão de óleo de peixe na ração de poedeiras eleva os níveis dos AGP $\omega$-3: alfa-linolênico, eicosapentanoico (EPA) e docosahexanoico (DHA) na gema de ovos comerciais (Briz, 1997; Quirino et al., 2009). Outro ingrediente utilizado são algas marinhas, produtoras primárias de AGP $\boldsymbol{\omega}$-3. As algas marinhas são os únicos seres capazes de sintetizar EPA e DHA, e os peixes, ao se alimentarem destas, se tornam fontes secundárias dos ácidos graxos (Piber Neto et al., 2009).

Os ácidos graxos são classificados conforme o número de duplas ligações, como: saturados (sem dupla ligação), monoinsaturados (uma dupla) e poliinsaturados. Os AGP são caracterizados por possuírem 18 ou mais átomos de carbono em sua estrutura química e duas ou mais insaturações. As principais séries de AGP são os ômegas 3 e 6 . A designação ômega $(\omega)$ está relacionada à posição da primeira dupla ligação, contando a partir do grupo metílico final da molécula de ácido graxo. Os AGP $\omega$-3 possuem a primeira dupla ligação entre o terceiro e o quarto átomo de carbono, enquanto os AGP $\omega$-6 têm a primeira dupla ligação entre o sexto e o sétimo átomo de carbono (Morris, 2003).

Os ácidos alfa-linolênico e linoleico são, respectivamente, precursores das séries dos AGP $\omega$-3 e $\boldsymbol{\omega}$-6. Esses lipídios são denominados ácidos graxos essenciais (AGE), pois mamíferos e aves não são capazes de sintetizá-los, sendo necessário adquiri-los pela dieta. Uma vez ingeridos, os AGE irão se alongar e dessaturar para dar origem a outros ácidos graxos. O ácido linoleico é convertido, por exemplo, em ácido araquidônico, e o ácido linolênico em EPA e DHA (Togashi et al., 2007; Novello et al., 2008).

Este estudo foi realizado para comparar os teores de ácidos graxos das gemas de ovos convencionais e modificados com ômega-3 e avaliar a influência desse ácido graxo nas características físicas dos ovos.

\section{Material e Métodos}

Foram coletados aleatoriamente 360 ovos marrons, tipo extra, envasados em embalagem de polietileno, produzidos em uma granja localizada em Marília, São Paulo, por poedeiras comerciais da linhagem Isa Brown alojadas em gaiolas de dimensões $45 \times 50 \times 45 \mathrm{~cm}\left(450 \mathrm{~cm}^{2} /\right.$ ave $)$. Na granja, 864 aves foram aleatoriamente distribuídas em dois grupos (onde cada gaiola com quatro aves foi considerada uma repetição) de modo a receber rações diferenciadas. No grupo 1,432 poedeiras foram alimentadas durante toda vida produtiva com ração à base de milho e farelo de soja (Tabela 1), sendo os ovos produzidos por estas aves denominados como ovos comerciais convencionais. No segundo grupo, a partir da $22^{\underline{a}}$ semana de idade, as aves foram alimentadas com ração contendo 1,5\% de substrato em pó de algas marinhas e 1,8\% de óleo de peixe (Tabela 2). Os ovos produzidos pelo grupo 2 receberam a nomenclatura de ovos modificados com ômega 3( $\omega$-3).

Durante os meses de fevereiro e março de 2008 foram coletados, aleatoriamente, uma vez por semana, 60 ovos frescos produzidos por poedeiras com 33 semanas de idade (11 semanas após o início do deferimento das aves segundo a dieta), sendo $50 \%$ classificados como ovos convencionais e, $50 \%$, ovos modificados com $\omega$-3, totalizando ao final de seis semanas 360 ovos.

No mesmo dia da coleta, os ovos foram transportados em caminhão sem refrigeração, do local de produção (Marília, São Paulo) até o CEASA do Rio de Janeiro, RJ, numa distância aproximada de 524 km e, em seguida, em carro de passeio nas mesmas condições, até o Laboratório de Análise de Ovos (LAO) do Instituto de Zootecnia da UFRRJ, localizado em Seropédica, RJ. O tempo decorrido entre a

Tabela 1 - Composição das dietas experimentais.

\begin{tabular}{|c|c|c|}
\hline \multirow[b]{2}{*}{ Ingrediente } & \multicolumn{2}{|c|}{ Dieta } \\
\hline & $\begin{array}{c}\text { Produção } \\
\text { de ovos } \\
\text { convencionais }\end{array}$ & $\begin{array}{c}\text { Produção } \\
\text { de ovos } \\
\text { modificados }\end{array}$ \\
\hline Milho & 60,44 & 59,17 \\
\hline Farelo de soja (46\%) & 25,80 & 25,98 \\
\hline Fosfato bicálcico (18\% P, 21\% Ca) & 1,93 & 1,94 \\
\hline Calcário & 8,87 & 8,86 \\
\hline Sal & 0,32 & 0,32 \\
\hline Óleo de peixe & 0,00 & 1,80 \\
\hline Óleo de soja & 0,71 & 0,00 \\
\hline Substrato de algas & 0,00 & 1,50 \\
\hline Areia & 1,50 & 0,00 \\
\hline Cloreto de colina $(60 \%)$ & 0,05 & 0,05 \\
\hline DL-metionina & 0,13 & 0,13 \\
\hline Suplemento mineral-vitamínico ${ }^{1}$ & 0,25 & 0,25 \\
\hline \multicolumn{3}{|l|}{ Composição nutricional calculada ${ }^{2}$} \\
\hline Energia metabolizável $(\mathrm{kcal} / \mathrm{kg})^{3}$ & 2800 & 2800 \\
\hline Proteína bruta (\%) & 17,18 & 17,07 \\
\hline Cálcio (\%) & 3,90 & 3,90 \\
\hline Fósforo disponível (\%) & 0,45 & 0,45 \\
\hline Sódio (\%) & 0,17 & 0,17 \\
\hline Metionina (\%) & 0,40 & 0,40 \\
\hline Metionina + cistina $(\%)$ & 0,69 & 0,69 \\
\hline Lisina (\%) & 0,89 & 0,89 \\
\hline Extrato etéreo (\%) & 5,96 & 6,99 \\
\hline Ácido linolênico (\%) & 0,00 & 0,89 \\
\hline Eicosapentaenoico (\%) & 0,00 & 0,45 \\
\hline Docosahexanoico (\%) & 0,00 & 0,71 \\
\hline \multicolumn{3}{|c|}{$\begin{array}{l}{ }^{1} \text { Adição por quilograma de dieta: vit. A - } 6250 \text { UI; vit. D - } 25.00 \text { UI; vit. E - } 12 \\
\text { UI; vit. K - 0,04 mg; tiamina - 0,25 mg; riboflavina - 3,40 mg; vitamina } \mathrm{B}_{6} \\
0,25 \mathrm{mg} \text { - vitamina B } \text { B }_{12} \text { - } 201 \text { g; ácido pantoténico - 3,80 mg; niacina - 9,90 mg; } \\
\text { biotina - 0,10 mg; ácido fólico - 0,25 mg; Cu - 6,00 mg; Fe - 52,50 mg; I - 0,33 mg; } \\
\text { Se - 0,21 mg; Mg - 48,0 mg; Zn - 60,23 mg; etoxiquina - 0,31 mg. } \\
2 \text { Composição calculada segundo Rostagno et al. (2005). } \\
{ }^{3} \text { Calculada segundo NRC (1994). }\end{array}$} \\
\hline
\end{tabular}

R. Bras. Zootec., v.39, n.8, p.1733-1739, 2010 
coleta dos ovos na granja até o laboratório para análise dos ovos foi de quatro dias.

As avaliações da unidade Haugh, índice de gema e espessura da casca foram realizadas no mesmo dia da chegada dos ovos ao LAO da UFRRJ, onde foram divididos em dois tratamentos segundo o seu teor de AGP $\omega$-3 (convencionais e modificados com $\omega$-3). Na análise qualitativa foi utilizado o delineamento em blocos ao acaso, no qual cada ovo foi considerado uma repetição, totalizando 180 repetições por tratamento. O modelo matemático utilizado foi:

$\mathrm{Y}_{\mathrm{ij}}=\mu+\mathrm{t}_{\mathrm{i}}+\mathrm{b}_{\mathrm{ij}}+\mathrm{e}_{\mathrm{ij}} \quad$ para $\mathrm{i}=1,2, \ldots$, a tratamentos

$\mathrm{j}=1,2, \ldots$, b blocos $\mu$ é a média geral

em que: $\mu=$ média paramétrica; $\mathrm{t}_{\mathrm{i}}=$ efeito fixo do i-ésimo tratamento (tipo de ovo segundo o teor de AGP $\omega$-3); $\mathrm{b}_{\mathrm{j}}=$ efeito fixo do j-ésimo bloco (número de coletas); e $\mathrm{e}_{\mathrm{ij}}=$ erro aleatório.

Para avaliação da qualidade interna, os ovos foram pesados em balança digital com precisão de 0,001 g, quebrados em uma superfície plana de vidro e, com um micrômetro tripé Ames modelo S-6428 (Masashutes, EUA), mediu-se a altura do albúmen denso. A unidade Haugh foi calculada através da fórmula proposta por Card \& Nesheim (1966), $\mathrm{UH}=100 \log \left(\mathrm{H}+7,57-1,7 \mathrm{~W}^{0,37}\right)$, em que $\mathrm{H}=$ altura do albúmen denso (mm) e $\mathrm{W}$ = peso do ovo (g). A aferição da altura da gema foi feita após ter sido separada do albúmen, utilizando o mesmo instrumento que mediu a altura do albúmen denso, e seu diâmetro tomado com um paquímetro analógico Mitutoyo, série 532, 0-150 mm ×0,02 mm (Tóquio, Japão). O índice de gema foi calculado através da razão entre a altura e o diâmetro desta estrutura (Sharp \& Powell, 1930).

Tabela 2 - Composição centesimal em ácidos graxos do substrato de algas marinhas e do óleo de peixe

\begin{tabular}{lcc}
\hline Ácido graxo & $\begin{array}{c}\text { Substrato } \\
\text { de algas } \\
\text { marinhas }\end{array}$ & $\begin{array}{c}\text { Óleo } \\
\text { de } \\
\text { peixe }\end{array}$ \\
\hline Mirístico & 23,36 & 15,51 \\
Palmítico & 43,61 & 24,63 \\
Esteárico & 2,16 & 4,14 \\
Total de ácidos graxos saturados & 69,13 & 44,28 \\
Palmitoleico & 4,34 & 11,03 \\
Oleico & 2,85 & 3,98 \\
Total de ácidos graxos monoinsaturados & 7,19 & 15,01 \\
Linoleico & 1,25 & 2,91 \\
Gamalinolênico & 1,23 & 1,21 \\
Araquidônico & 1,79 & 2,62 \\
Total de poliinsaturados da série ômega-6 & 4,27 & 6,74 \\
Linolênico & 1,40 & 0,99 \\
Eicosapentaenoico (EPA) & 1,71 & 15,62 \\
Docosahexanoico (DHA) & 16,30 & 17,36 \\
Total de ácidos graxos poliinsaturados & & \\
da série ômega-3 & 19,41 & 33,97 \\
Relação entre $\omega$-6/ $\omega-3$ & 0,22 & 0,20 \\
\hline
\end{tabular}

Para avaliação da qualidade externa, as cascas foram lavadas em água corrente de forma que as membranas interna e externa fossem preservadas. Depois de secas em estufa ventilada a $55^{\circ} \mathrm{C}$ por 5 horas, mediu-se a espessura de fragmentos das zonas apical, equatorial e basal das cascas com um micrômetro analógico de pressão Mitutoyo, série 7, modelo 7313, 0-10 mm × 0,01 mm (Tóquio, Japão) e com a média destes três pontos obteve-se os dados de espessura da casca.

Imediatamente após a avaliação da qualidade interna dos ovos, três pools de 10 gemas de cada tratamento foram direcionados ao Laboratório de Análise de Alimentos e Bebidas (LAAB) do Instituto de Tecnologia da UFRRJ, para determinação dos níveis de ácidos graxos. Nesta segunda análise, foi utilizado o delineamento em blocos ao acaso considerando cada pool de 10 gemas como uma repetição, totalizando três repetições por tratamento. O modelo matemático utilizado foi:

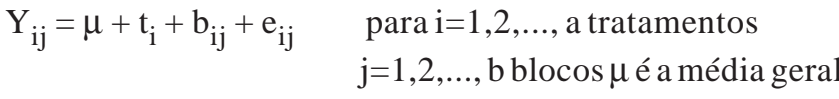
em que: $\mu$ = média paramétrica; $t_{i}=$ efeito fixo do i-ésimo tratamento (tipo de ovo segundo o teor de AGP $\omega$-3); $b_{j}=$ efeito fixo do j-ésimo bloco (número de coletas); e e $\mathrm{i}_{\mathrm{ij}}=$ erro aleatório.

A extração dos lipídios foi realizada segundo o método de Folch et al. (1957). Foi pesado 0,5 g de gema crua em balança analítica 0,0001 g modelo RS 232 - Mettler Toledo (Greifensee, Suíça), transferida para balão volumétrico de $100 \mathrm{~mL}$, sendo seu volume completado com solução 2:1 de clorofórmio e metanol. A mistura foi agitada manualmente por dois minutos e, em seguida, filtrada em funil de separação Squibb. Foi adicionado ao funil $20 \mathrm{~mL}$ de $\mathrm{KCl}$ 0,72\% para a primeira separação de fases. Foi adicionado mais $17,5 \mathrm{~mL}$ de $\mathrm{KCl}$ 0,72\% e a mistura agitada manualmente. Após a segunda separação das fases, o extrato clorofórmico foi filtrado com sulfato de sódio anidro $\left(\mathrm{Na}_{2} \mathrm{SO}_{4}\right)$ para um balão de fundo redondo de $200 \mathrm{~mL}$. Secou-se o extrato clorofórmico em rota-evaporador a $25^{\circ} \mathrm{C}$ e, em seguida, foi determinada a quantidade de lipídeos totais.

A metilação e saponificação dos lipídeos foram realizadas utilizando-se o método de Hartman e Lago (1973). Amostras de $1 \mathrm{~mL}$ da solução lipídica do extrato clorofórmico foram transferidas para tubos de tampa esmerilhada, seguida de evaporação do clorofórmio com auxílio de corrente de nitrogênio. A saponificação resultou da adição de $2 \mathrm{~mL}$ de solução metanólica de hidróxido de sódio a $0,5 \mathrm{~N}$ e aquecimento em banho-maria a $100^{\circ} \mathrm{C}$ por cinco minutos.

Para esterificação dos ácidos graxos, foi adicionado ao extrato lipídico $6 \mathrm{~mL}$ do reagente de esterificação $(60 \mathrm{~mL}$ de 
metanol +2 g de cloreto de amônio $+3 \mathrm{~mL}$ de ácido sulfúrico), com aquecimento dos tubos em água fervente por três minutos. Após o resfriamento, foi adicionado ao extrato $5 \mathrm{~mL}$ de água fria, seguida de agitação manual. A fase superior foi transferida para um tubo de ensaio e adicionado $5 \mathrm{~mL}$ de solução saturada de carbonato de sódio $\left(\mathrm{NaHCO}_{3}\right)$. Em seguida, foram aplicadas três porções consecutivas de $1 \mathrm{~mL}$ de hexano, para que assim fossem extraídos os ésteres metílicos do composto.Uma alíquota de $1 \frac{1}{1} 4 \mathrm{~L}$ do extrato esterificado foi injetada no cromatógrafo à gás, modelo Intecrom G8000 (São Paulo, Brasil), equipado com detector de ionização em chama (FID), injetor split e coluna CP-SIL 88.

A identificação dos ácidos graxos foi realizada através da comparação dos tempos de retenção dos ésteres metílicos das amostras padrões de ácidos graxos autênticos (Sigma, EUA). A quantificação dos ácidos graxos foi realizada por área dos picos observados.

Os resultados foram submetidos à análise de variância e as médias comparadas pelo teste $\mathrm{F}$, com 5\% de significância, utilizando o software Sisvar 4.6 (Ferreira, 2003).

\section{Resultados e Discussão}

Não foi observada diferença $(\mathrm{P}>0,05)$ entre as médias de peso dos ovos estudados (Tabela 3); tanto os ovos convencionais quanto os modificados com $\omega$-3 foram classificados como extra, peso médio entre 60 e 65 g por unidade, como determinado pela legislação brasileira (Brasil, 1991). Apesar de não haver diferença estatística entre os dois tipos de ovos ( $\mathrm{P}>0,05)$, observou-se que os ovos convencionais apresentaram maiores médias para peso do ovo quando comparados aos ovos modificados com $\omega$-3 (Tabela 3). Estudos mostram que a incorporação de ácidos graxos poliinsaturados na ração de poedeiras induz à diminuição no tamanho e peso da gema, ocasionando redução do peso total dos ovos (Whitehead et al., 1993; Costa et al., 2008a).

Não foi observada diferença $(\mathrm{P}>0,05)$ entre as médias de espessura da casca nos ovos convencionais e

Tabela 3 - Peso e qualidade externa e interna de ovos comerciais convencionais e modificados com $\omega$-3

\begin{tabular}{lcccc}
\hline $\begin{array}{l}\text { Parâmetro } \\
\text { avaliado }\end{array}$ & Convencional & $\begin{array}{c}\text { Modificado } \\
\text { com } \omega \text {-3 }\end{array}$ & $\begin{array}{c}\text { CV } \\
(\%)\end{array}$ & $\begin{array}{c}\text { Valor } \\
\text { de P }\end{array}$ \\
\hline $\begin{array}{l}\text { Peso dos ovos (g) } \\
\text { Espessura de }\end{array}$ & 64,00 & 62,66 & 3,01 & 0,1826 \\
casca (mm) & 0,380 & 0,382 & 6,18 & 0,8304 \\
Unidade Haugh & 63,41 & 60,44 & 3,14 & 0,1484 \\
Índice de gema & 0,42 & 0,34 & 6,14 & 0,0041 \\
\hline
\end{tabular}

Médias diferem $(\mathrm{P}<0,05)$ pelo teste $\mathrm{F}$.

$\mathrm{CV}$ - coeficiente de variação. modificados com $\omega$-3 (Tabela 3). Alguns autores relatam que a adição de ácidos graxos em excesso na ração de poedeiras pode provocar declínio na qualidade externa dos ovos em virtude destes lipídios formarem sais insolúveis com o cálcio no intestino delgado das aves, dificultando, assim, a mobilização desse mineral pelas poedeiras (Muramatsu et al., 2005; Costa et al., 2008b). No entanto, Garcia-Rebollar et al. (2008), ao avaliarem níveis de inclusão de óleo de peixe em rações de poedeiras semelhante ao utilizado no presente estudo (1,75\%) não verificaram diferença entre as médias de espessura da casca dos ovos convencionais e dos modificados com $\omega$-3. A justificativa dos autores foi que a concentração de óleo de peixe utilizada na dieta não foi suficiente para provocar queda na qualidade externa dos ovos produzidos por poedeiras alimentadas com dietas suplementadas com este ingrediente.

Para Unidade Haugh, não houve diferença entre as médias dos dois tipos de ovos analisados, sendo que as médias observadas neste experimento (63,41 e 60,44; para os ovos convencionais e modificados com $\omega$-3, respectivamente) estão de acordo com os valores descritos no Manual de Classificação de Ovos, que considera, para ovos com 4 a 6 dias de idade, armazenados em temperatura ambiente, classificação A (entre 72 e 55 UH), o que indica boa qualidade interna (USDA, 2000).

As médias de índice de gema observadas neste experimento (0,42 e 0,34 para ovos convencionais e modificados com $\omega-3$, respectivamente) estão dentro da faixa padrão de 0,30 a 0,50 estabelecida para ovos frescos (Romanoff \& Romanoff, 1949). Como este parâmetro determina a consistência e qualidade da gema, observa-se que tanto ovos convencionais quanto os modificados com $\omega$-3 estão dentro do padrão de qualidade (Stadelman \& Cotterill, 1995). Entretanto, foram observadas médias de índice de gema inferiores $(\mathrm{P}<0,05)$ para ovos modificados com $\omega$-3 quando comparados aos ovos convencionais (Tabela 3). Estudos mostram que uma dieta com elevados teores de ácidos graxos poliinsaturados pode interferir na formação da gema, alterando sua consistência e deixando-a mais susceptível a rompimentos (Watkins, 2003).

Os ácidos graxos saturados (AGS) identificados foram o mirístico, palmítico e esteárico. Os ovos modificados com $\omega$-3 apresentaram menores médias $(\mathrm{P}<0,05)$ de ácido mirístico e palmítico, no entanto, com relação ao ácido esteárico, não foram observadas diferenças $(\mathrm{P}>0,05)$ entre as médias dos dois tipos de ovos estudados (Tabela 4). Em estudo semelhante, Piber Neto et al. (2009) verificaram que ovos modificados com $\omega$-3 apresentaram menores teores de ácido mirístico do que ovos produzidos de forma convencional. No entanto, com relação aos ácidos palmítico 
e esteárico, os autores não verificaram diferença entre os dois tipos de ovos. Os ovos modificados com $\omega$-3 apresentaram um total de ácidos graxos saturados (mirístico + palmítico + esteárico) 31,6\% inferior quando comparado aos ovos convencionais (Tabela 4). Segundo Mourthé et al. (2005), a variação dos níveis de AGS na gema está relacionada à substituição destes pelos ácidos graxos poliinsaturados $\omega$-3 ingeridos na dieta.

Os ácidos graxos monoinsaturados (AGMI) identificados foram os ácidos palmitoleico e oleico. Os ovos modificados com $\omega$-3 apresentaram as maiores médias $(\mathrm{P}<0,05)$ de ácido oleico, no entanto, no que se refere ao ácido palmitoleico, não foram observadas diferenças $(\mathrm{P}>0,05)$. Com relação aos níveis de AGMI totais (pamitoleico + oleico), as maiores médias $(\mathrm{P}<0,05)$ foram observadas nos ovos modificados com $\omega$-3 (Tabela 4). Esses resultados divergem dos descritos por Mori (2001) que, objetivando a produção de ovos modificados com $\omega$-3 a partir da adição de óleos de peixe e de linhaça na ração de aves de postura, verificou que à medida que aumentava os níveis dietéticos de ácidos graxos poliinsaturados da série ômega-3 (AGP $\omega$-3), diminuía o teor de AGMI totais da gema. Neste estudo, o maior teor de ácido oleico nos ovos modificados com $\omega$-3, quando comparado aos ovos convencionais, não pode ser facilmente explicado, uma vez que era esperado que o excesso de AGP $\omega$-3, induzido pela inclusão de óleo de peixe e algas marinhas na dieta das poedeiras, promovesse a inibição da atividade da enzima formadora de ácido oleico, ocasionando redução da concentração deste ácido graxo na gema dos ovos (Cherian \& Sim, 1991).
Os ácidos graxos poliinsaturados da série ômega-6 (AGP $\omega$-6) identificados foram os ácidos linoleico e araquidônico (Tabela 4). Os ovos produzidos de forma convencional apresentaram maiores médias $(\mathrm{P}<0,05)$ de ácidos linoleico, araquidônico e AGP $\omega$-6 totais (linoleico + araquidônico) em comparação com os ovos modificados com $\omega$-3. Estes resultados assemelham-se aos encontrados por Carvalho et al. (2009a), que, ao investigarem a modificação do teor de ácidos graxos de gemas de ovos comerciais, verificaram médias menores de ácidos linoleico e araquidônico para ovos modificados com $\omega$-3 quando comparados aos convencionais. Pesquisas mostram que os ácidos graxos essenciais, linoleico ( $\omega$-6) e alfa-linolênico $(\omega-3)$, são controlados pelas mesmas enzimas dessaturases e alongases. Esse fato promove a competição entre séries ômega 6 e 3, de modo que a ingestão em excesso de AGP $\omega$-3 limita a conversão dos AGP $\omega$-6 no organismo animal e vice e versa (Santos et al., 2007a). Em estudo semelhante, Mazalli \& Bragagnolo (2007) verificaram valores significativamente menores de ácido araquidônico para ovos modificados com $\omega$-3 quando comparado aos convencionais. A maior disponibilidade de AGP $\omega$-3 na dieta reduz os teores de ácido araquidônico tanto devido à inibição do seu catabolismo quanto à formação deste ácido a partir do ácido linoleico (Raes et al., 2002).

Os ácidos graxos poliinsaturados da série ômega - 3 (AGP $\omega$-3) identificados foram o alfa-linolênico, eicosapentaenoico (EPA) e docosahexanoico (DHA) (Tabela 4). Os ovos modificados com $\omega$-3 apresentaram as maiores médias $(\mathrm{P}<0,05)$ de ácidos alfa-linolênico, EPA, DHA e AGP $\omega$-3 totais (alfa-linolênico + EPA + DHA).

Tabela 4 - Teores de ácidos graxos na gema (mg/100 g de gema) de ovos convencionais e modificados com $\omega$-3

\begin{tabular}{|c|c|c|c|c|c|}
\hline Ácido graxo & Sigla & Convencional & $\begin{array}{c}\text { Modificado } \\
\text { com } \omega-3\end{array}$ & CV (\%) & $\begin{array}{l}\text { Valor } \\
\text { de P }\end{array}$ \\
\hline Mirístico & C14:0 & 880 & 635 & 5,24 & 0,0046 \\
\hline Palmítico & C16:0 & 6410 & 4255 & 8,67 & 0,0002 \\
\hline Esteárico & C18:0 & 1450 & 1750 & 9,99 & 0,1420 \\
\hline Total de ácidos graxos saturados & & 8740 & 6640 & 5,08 & 0,0039 \\
\hline Palmitoleico & C16:1 & 3040 & 4004 & 10,23 & 0,5515 \\
\hline Oleico & C18:1 & 4957 & 6740 & 6,21 & 0,0224 \\
\hline Total de ácidos graxos monoinsaturados & & 7997 & 10744 & 4,20 & 0,0316 \\
\hline Linoleico & C18:2 & 9210 & 5260 & 4,40 & 0,0468 \\
\hline Araquidônico & C20:4 & 390 & 250 & 11,11 & 0,0082 \\
\hline Total de ácidos graxos poliinsaturados da série $\boldsymbol{\omega}$-6 & & 9600 & 5510 & 3,26 & 0,0139 \\
\hline Alfa-linolênico & C18:3 & 880 & 1618 & 6,23 & 0,0331 \\
\hline Eicosapentaenoico (EPA) & C20:5 & NI & 45 & 40,25 & 0,0001 \\
\hline Docosahexanoico (DHA) & C22:6 & 47 & 176 & 7,94 & 0,0024 \\
\hline Total de ácidos graxos poliinsaturados da série $\omega$-3 & & 927 & 1839 & 5,93 & 0,004 \\
\hline Total de ácidos graxos poliinsaturados & & 10527 & 7349 & 15,24 & 0,0673 \\
\hline
\end{tabular}

Médias diferem $(\mathrm{P}<0,05)$ pelo teste $\mathrm{F}$.

CV - coeficiente de variação (\%).

NI - não-identificado. 
Estes resultados corroboram com Simopoulos (2000), que relatou que ovos modificados com $\omega$-3 possuem quantidades expressivas de ácidos alfa-linolênico, EPA e DHA. Já com relação aos ovos convencionais, os resultados observados estão de acordo com a Tabela Brasileira de Composição de Alimentos (2004), a qual considera o ovo produzido de forma convencional naturalmente deficiente em alfa-linolênico ( $700 \mathrm{mg} / 100 \mathrm{~g}$ de gema), DHA (<50 mg/ $100 \mathrm{~g}$ de gema) e deficiente também por não possuir EPA em sua composição. Os ovos modificados com $\omega$-3 apresentaram média de AGP $\omega$-3 totais (alfa-linolênico + EPA + DHA) 41,0\% superior aos convencionais (Tabela 4). Esses resultados corroboram com Grobas \& Mateos (2000), os quais constataram que a composição em ácidos graxos poliinsaturados da gema do ovo pode ser influenciada pela dieta da ave. De acordo com Noble et al. (1996), a maior parte da composição lipídica do ovo é formada no fígado da poedeira antes mesmo da gema ser depositada no ovo, permitindo, deste modo, que a galinha possua melhor controle das características lipídicas da gema. No entanto, a modificação hepática não é completa, o que permite que a gordura ingerida pelas poedeiras através da dieta influencie na composição lipídica da gema, especialmente quanto ao conteúdo de ácidos graxos poliinsaturados. Estudos mostram que substratos de algas marinhas e óleo de peixe, ingredientes ricos em AGP $\omega$-3, quando incorporados à dieta de poedeiras, são capazes de aumentar o teor destes lipídios na gema dos ovos. Carvalho et al. (2009b), ao avaliarem o efeito da inclusão de fontes marinhas de ácidos graxos poliinsaturados na ração de poedeiras da linhagem Hisex White, verificaram que a maior incorporação de ácidos graxos poliinsaturados $\omega$-3 ocorreu na gema dos ovos de aves alimentadas com óleo de peixe (218,62 mg/gema), seguidas por aquelas arraçoadas com algas marinhas (104,18 mg/gema), quando comparados aos ovos de poedeiras alimentadas com ração a base de milho e farelo de soja (62,16 mg/gema).

Não foi observada diferença $(\mathrm{P}>0,05)$ entre as médias da relação de ácidos graxos poliinsaturados e saturados (P/S) dos dois tipos de ovos estudados (Tabela 5). Esses resultados são semelhantes ao encontrado por Mori (2001), que ao estudar o efeito da inclusão de 2,0\% de óleo de peixe na ração de poedeiras comerciais, não verificou diferença entre as médias da relação poliinsaturados/saturados entre ovos produzidos de forma convencional e modificados com $\omega$-3. A justificativa do autor para o fato, assim como observado neste estudo, foi que o teor total de AGP parece não sofrer alterações mesmo com a utilização de óleo de peixe como ingrediente "modificador" do teor de ácidos graxos dos ovos comerciais.
Tabela 5 - Relações entre ácidos graxos na gema de ovos convencionais e modificados com $\omega$-3

\begin{tabular}{lcccc}
\hline $\begin{array}{l}\text { Relações entre } \\
\text { ácidos graxos }\end{array}$ & Convencional & $\begin{array}{c}\text { Modificado } \\
\text { com } \omega \text {-3 }\end{array}$ & $\begin{array}{c}\text { CV } \\
(\%)\end{array}$ & $\begin{array}{c}\text { Valor } \\
\text { de P }\end{array}$ \\
\hline $\begin{array}{l}\text { Poliinsaturados e } \\
\text { saturados }(\mathrm{P} / \mathrm{S})\end{array}$ & 0,93 & 1,10 & 3,79 & 0,0899 \\
$\begin{array}{l}\text { Poliinsaturados } \\
\text { da série } \omega \text {-6 e }\end{array}$ & & & & \\
$\omega$-3 $(\omega$ - $6 / \omega$-3) & 10,36 & 3,00 & 6,24 & 0,0026
\end{tabular}

Médias diferem $(\mathrm{P}<0,05)$ pelo teste $\mathrm{F}$.

CV - coeficiente de variação (\%)

A relação entre os teores totais dos ácidos graxos poliinsaturados das séries $\omega$-6 e $\omega$-3 $(\omega-6 / \omega$-3) dos ovos convencionais foi significativamente superior $(\mathrm{P}<0,05)$ aos dos ovos modificados com $\omega$-3 (Tabela 5). O resultado encontrado para os ovos modificados com $\omega$-3 são considerados satisfatórios, pois de acordo com diversos estudos, para que se tenha um balanço correto da cadeia de transformação dos ácidos graxos essenciais, o consumo de $\omega$-6/ $\omega$-3 deve ser no máximo 4:1 (Simopoulos, 2000; Furuya et al., 2006). Estudos mostram que a ingestão dos ácidos graxos essenciais desencadeia uma série de reações químicas mediadas por enzimas desaturases e elongases no organismo animal. Estes lipídios são convertidos em outros ácidos de cadeia longa, como o araquidônico, EPA e DHA. Nestas reações há competição entre estas enzimas, de modo que a ingestão em excesso de ácidos graxos poliinsaturados $\omega$-6 limita a formação dos AGP $\omega$-3 no organismo animal e vice-versa (Santos et al., 2007b).

\section{Conclusões}

Ovos modificados com ômega-3 apresentam teores de ácidos graxos monoinsaturados e poliinsaturados da série $\omega$-3 superiores aos dos ovos convencionais, ao passo que as maiores médias dos ácidos graxos saturados e poliinsaturados da série ômega-6 são observadas para os ovos convencionais. Ambos os tipos de ovos apresentam boas características de qualidade interna e externa.

\section{Referências}

BRASIL. MINISTÉRIO DA AGRICULTURA, PECUÁRIA E ABASTECIMENTO. Resolução CIPOA n 005, de 19 de novembro de 1991. Diário Oficial da República Federativa do Brasil n 78. Brasília, 1991.

BRIZ, R.C. Ovos com teores mais elevados de ácidos graxos ômega 3. In: SIMPÓSIO TÉCNICO DE PRODUÇÃO DE OVOS, 7., 1997, São Paulo. Anais... São Paulo: Associação Paulista de Avicultura, 1997, p.153-193.

CARD, L.E.; NESHEIM, M.C. Poultry production. Philadelphia: Lea \& Febiger, 1966. 399p. 
CARVALHO, P.R.; PITA, M.C.G.; PIBER NETO, E. et al. Efeito de fontes marinhas ricas em PUFAs na dieta a composição lipídica e percentuais de incorporação de PUFAs n-6 na gema do ovo. Arquivos do Instituto Biológico, v.76, n. 2, p.173-186, 2009a.

CARVALHO, P.R.; PITA, M.C.G.; PIBER NETO, E. et al. Influência da adição de fontes marinhas ricas em PUFAs na dieta sobre a composição lipídica e percentuais de incorporação de PUFAs n-3 na gema do ovo. Arquivos do Instituto Biológico, v.76, n.1, p.27-39, 2009b.

CHERIAN, G.; SIM, J.S. Effect of feeding full fat flax and canola seeds to laying hens on the fatty acid composition of eggs, embryos, and newly hatched chicks. Poultry Science, v.70, p.917-922, 1991.

COSTA, F.G.P.; SOUZA, J.G.; SILVA, J.H.V. et al. Influência do óleo de linhaça sobre o desempenho e a qualidade dos ovos de poedeiras semipesadas. Revista Brasileira de Zootecnia, v.37, n.5, p.861-868, 2008a.

COSTA, F.G.P.; SOUZA, C.J.; GOULARD, C.C. et al. Desempenho e qualidade dos ovos de poedeiras semipesadas alimentadas com dietas contendo óleos de soja e canola. Revista Brasileira de Zootecnia, v.37, p.1412-1418 n.8, 2008b.

FERREIRA, D.F. Sistema de análise de variância - Sisvar. Versão 4.6 (Build 6.0). Lavras: DEX/UFLA, 2003.

FOLCH, J.; LESS, M.; STANLEY, S. A simple method for the isolation and purification of total lipids from animal tissues. Journal of Biological Chemistry, v.226, n.1, p.497-509, 1957.

FURUYA, W.M.; HAYASHI, C.; SILVA, A.B.M. et al. Composição centesimal e perfil de ácidos graxos do camarão-d'água-doce. Revista Brasileira de Zootecnia, v.35, n.4, p.1577-1580, 2006.

GARCIA-REBOLlAR, P.; CACHALDORA, P.; ALVAREZ, C. et al. Effect of the combined supplementation of diets with increasing levels of fish and linseed oils on yolk fat composition and sensorial quality of eggs in laying hens. Animal Feed Science and Technology, v.140, p.337-348, 2008.

GROBAS, S.; MATEOS, G.G. Influencia de la nutrición sobre la composición nutricional del huevo. In: CURSO DE ESPECIALIZACIÓN FEDNA, 12., 1996, Madrid. Avances em nutrición y alimentación animal. Madrid: Fedna, 2000. p.219-244.

HARTMAN, L.; LAGO, R.C.A. Rapid preparation of fatty acid methyl ester from lipids. Londres: Lab. Pract., v.22, p.475-476, 1973.

MADRUGA, M.S.; VIEIRA, T.R.L.; CUNHA, M.G.G. et al. Efeito de dietas com níveis crescentes de caroço de algodão integral sobre a composição química e o perfil de ácidos graxos da carne de cordeiros Santa Inês. Revista Brasileira de Zootecnia, v.37, n.8, p. 1496-1502, 2008.

MAZALLI, M.R.; BRAGAGNOLO, N. Validation of two methods for fatty acids analysis in eggs. Lipids, v.42, p.483-490, 2007.

MORI, A.V. Utilização de óleo de peixe e linhaça na ração como fontes de ácidos graxos poliinsaturados ômega-3 em ovos. 2001. 162f. Tese (Doutorado em Clínica Médica) Faculdade de Medicina Veterinária e Zootecnia/Universidade de São Paulo, Pirassununga.

MORRIS, D.H. [2003]. The novel egg: Opportunities for flax in omega-3 egg production. Winnipeg: Flax Council of Canada. 13p. Disponível em: <http://www.flaxcouncil.ca/ english/pdf/novelegg.pdf>. Acesso dia: 08/05/2008.

MOURTHÉ, K.; MARTINS, R.T.; AFONSO, R.J.C.F. Comparação do teor dos principais ácidos graxos de ovos comerciais e ovos enriquecidos com ácidos graxos polinsaturados ômega-3. Revista Higiene Alimentar, v.19, n.136, p. 32-35, 2005.

MURAMATSU, K.; STRINGHINI, J.H.; CAFÉ, M.B. et al. Desempenho, qualidade e composição de ácidos graxos do ovo de poedeiras comerciais alimentadas com rações formuladas com milho ou milheto contendo diferentes níveis de óleo vegetal. Acta Scientiarum. Animal Sciences, v.27, n.1, p.43-48, 2005.

NOBLE, R.C.; SPEAKE, B.K.; MCCARTNEY, R. et al. Yolk lipids and their fatty acids in the wild and captive ostrich (Struthio camelus). Comparative Biochemistry and Physiology, v.113B, n.4, p.753-756, 1996.

NOVELLO, D.; OST, P.R.; FONSECA, R.A. et al. Avaliação bromatológica e perfil de ácidos graxos da carne de frangos de corte alimentados com rações contendo farinha de peixe ou aveia-branca. Revista Brasileira de Zootecnia, v.37, n.9, p.1660-1668, 2008.

NATIONAL RESEARCH COUNCIL - NRC. Nutrient requirements of poultry. 9.ed. Washington D.C.: National Academy Press, 1994. 155p.

PIBER NETO, E.; CARVALHO, P.R.; PITA, M.C.G. et al. Egg's enrichment: utilization of fish oils and marine algae as sources of omega-3. Research Journal of Animal and Veterinary Sciences, v.4, p. 45-54, 2009.

QUIRINO, B.J.S.; COSTA, F.G.P.; QUEIROGA, R.C.R.E. et al. Effect of different metabolizable energy and soybean oil levels in the diet of laying hens on the egg chemical composition and lipid profile. Revista Brasileira de Zootecnia, v.38, n.4, p.685-689, 2009.

RAES, K.; HUYGHEBAERT, G.; DE SMET, S. et al. The deposition of conjugated linoleic acid in eggs of laying hens fed diets varying in fat level and fatty acid profile. Journal of Nutrition, v.132, p.182-189, 2002.

ROMANOFF, A.L.; ROMANOFF, A.J. The avian egg. New York: John Wiley, 1949. 918p.

ROSTAGNO, H.S.; ALBINO, L.F.T.; DONZELE, J.L. et al. Tabelas brasileiras para aves e suínos: composição de alimentos e exigências nutricionais. 2.ed. Viçosa, MG: Universidade Federal de Viçosa, 2005. 186p.

SANTOS, L.D.; FURUYA, W.M.; MATSUSHITA, M. et al. Deposição de ácido linoléico conjugado (CLA) em tilápias-do-nilo. Revista Brasileira de Zootecnia, v.36, n.5, p.1225-1230, 2007a.

SANTOS, L.D.; FURUYA, W.M.; MATSUSHITA, M. et al. Ácido linoléico conjugado (CLA) em dietas para tilápia-do-nilo: desempenho produtivo, composição química e perfil de ácidos graxos. Revista Brasileira de Zootecnia, v.36, n.5, p.1481-1488, 2007b.

SHARP, P.F.; POWELL, C.K. Decrease in internal quality of hen's eggs during storage as by the yolk. Industrial \& Engineering Chemistry Research, v.22, p.909-910, 1930.

SIMOPOULOS, A.P. Human requirement for N-3 polyunsaturated fatty acids. Poultry Science, v.79, p.961-970, 2000.

STADELMAN, W.J.; COTTERILL, O.J. Egg science and technology. New York/London: Food Products Press, 1995. 323p.

TABELA BRASILEIRA DE COMPOSIÇÃO DE ALIMENTOS, Campinas - SP, [2004]. Disponível em: <http://www.unicamp.br/ nepa/taco/tabela.php?ativo=tabela>. Acesso em: 4/5/2008.

TOGASHI, C.K.; FONSECA, J.B.; SOARES, R.T.R.N. et al. Composição em ácidos graxos dos tecidos de frangos de corte alimentados com subprodutos de maracujá. Revista Brasileira de Zootecnia, v.36, n.6, p.2063-2068, 2007.

UNITED STATES DEPARTAMENT OF AGRICULTURE - USDA. [2000]. Egg grading manual. Disponível em: <http:// www.ams.usda.gov/poultry/pdfs/EggGrading\%20manual.pdf > Acesso em: 12/4/2007.

WATKINS, B.A. CLA alters the fatty acid composition and physical properties of egg yolk and albumen. Journal of Agricultural and Food Chemistry, v.51, p.6870-6876, 2003.

WHITEHEAD, C.C.; BOWMAN, A.S.; GRIFFIN, H.D. Regulation of plasma oestrogens by dietary fats in the laying hen: Relationships with egg weight. British Poultry Science, v.34, p.999-1010, 1993. 